Yeshiva University, Cardozo School of Law

LARC @ Cardozo Law

Articles

Faculty

2004

\title{
Why are There Four Hegelian Judgments
}

David G. Carlson

Benjamin N. Cardozo School of Law, dcarlson@yu.edu

Follow this and additional works at: https://larc.cardozo.yu.edu/faculty-articles

Part of the Law Commons

\section{Recommended Citation}

David G. Carlson, Why are There Four Hegelian Judgments, 3 Cardozo Public Law, Policy, and Ethics Journal 143 (2004).

Available at: https://larc.cardozo.yu.edu/faculty-articles/20

This Article is brought to you for free and open access by the Faculty at LARC @ Cardozo Law. It has been accepted for inclusion in Articles by an authorized administrator of LARC @ Cardozo Law. For more information, please contact larc@yu.edu. 


\section{WHY ARE THERE FOUR HEGELIAN JUDGMENTS?}

\section{David Gray Carlson*}

Hegel is the philosopher of threes. In the Encyclopedia system, there is logic-nature-spirit. Within logic, there is being-essence-notion. Within notion, there is subject-object-idea. Within subjectivity, there is notion-judgment-syllogism. Yet, as everyone notices, when it comes to judgment, the structure is tetrachotomous. Here we find existence-reflection-necessity-notion. Why should there be four judgments when there are only three of everything else? Why must Shemp intrude upon the sublime perfection of Moe, Larry, and Curly? What need we d'Artagnan when Porthos, Athos, and Aramis seem the perfect threesome? Three's company. Four's a crowd!

In the Science of Logic, ${ }^{1}$ Hegel does not allude very directly to the change, but in the Encyclopedia Logic, Hegel explains:

[T] he different species of judgement derive their features from the universal forms of the logical idea itself. If we follow this clue, it will supply us with three chief kinds of judgement parallel to the stages of Being, Essence, and Notion. The second of these kinds, as required by the character of Essence, which is the stage of differentiation, must be doubled ... [W] [Wen the Notion, which is the unity of Being and Essence in a comprehensive thought, unfolds ... it must reproduce these two stages in a transformation proper to the notion. ${ }^{2}$

In this passage, Hegel suggests that it is the function of judgment to replay the objective logic, which had sublated itself at the end of essence. In the course of this dumb show for the sake of subjective notion, essence is the twice-told tale. Essence is the realm of mediation, so that judgment must be immediate, twice mediated, and notional (i.e., triune).

* Professor of Law, Benjamin N. Cardozo School of Law. Thanks to Jeanne Schroeder for comments on some early drafts.

1 G.W.F. Hegel, Hegel's SCienCe of Logic (A.V. Miller trans., 1969) [hereinafter SL]; For the German text, see G.W.F. HEGEL, WISSENSCHAFT DER LOGIK (Georg Lasson ed., 1975) [hereinafter WL].

2 G.W.F. Hegel, Hegel's Logic $\$ 171$, at 236 (William Wallace trans., 1975). 
Hegel returns to tetrachotomy of his method in his last chapter, where he writes that the negative moment is a correlative and an immediate negation, both of which must be counted:

If one insists on counting, this second immediate [i.e., the negation of the negation] is, in the course of the method as a whole, the third term to the first immediate and the mediated. It is also, however, the third term to the first or formal negative and to absolute negativity or the second negative; now as the first negative is already the second term, the term reckoned as third can also be reckoned as fourth, and instead of a triplicity, the abstract form may be taken as a quadruplicity; in this way, the negative or the difference is counted as a duality. ${ }^{3}$

Hegel does not limit the above remark to judgment. Perhaps he is saying that throughout the subjective logic, where the notion reestablishes its own reality, there is always quadruplicity, since mediation (i.e., negativity) is always both a mediation and an immediacy. If so, the question arises why only the judgment chapter and, we should add, the first third of syllogism, are overtly tetradic in form.

No doubt there is cause to suspect that the intrusion of tetrachotomy is a non-event unworthy of our attention. In the introduction to the Science of Logic, Hegel suggests that the only valid exposition of philosophy is one that conforms to the "simple rhythm" of method, which is arguably triune. The divisions, headings, sections, and chapters serve only

to facilitate a preliminary survey and strictly are only of historical value. They do not belong to the content and body of the science but are compilations of an external reflection which has already run through the whole of the exposition and consequently knows and indicates in advance the sequence of its moments before these are brought forward by the subject matter itself. ${ }^{5}$

In other words, Hegel, having worked through the system, inserts the headings solely for expositional convenience. The headings have nothing to do with the logic. This leads one to believe that perhaps we

$3 \mathrm{SL}$, supra note 1, at 836; $2 \mathrm{WL}$, supra note 1 , at 498.

$4 \mathrm{SL}$, supra note 1 , at 54; $1 \mathrm{WL}$, supra note 1 , at 35.

$5 \mathrm{SL}$, supra note 1, at 54-55; $1 \mathrm{WL}$, supra note 1, at 35. 
should make nothing at all out of the quadripartite headings in Judgment.

Shall we say that tetrachotomy is simply an error by Hegel? There is some reason to think so. In Measure, Hegel denounces Kant's table of categories precisely because they are tetrachotomous. ${ }^{6}$ No triplicity inheres between Kant's quantity, quality, relation, and modality, Hegel complains. For this very reason, Hegel writes, Kant "was unable to hit on the third to quality and quantity." Hegel implies that modality was Kant's true third-a term Hegel equates with Measure. Relation - the nominal third-is dismissed as merely an "insertion."

In spite of his measured "quadrophobia," Hegel's judgments correspond to Kant's table of the logical functions of judgment from the Critique of Pure Reason. Yet, Kant says, the logical forms of judgment are directly connected to the very table of categories that Hegel has criticized. ${ }^{9}$ According to the table of the logical functions in judgment:

6 Kant's categories are as follows: I. Of Quantity —Unity. Plurality. Totality.; II. Of Quality-Reality. Negation. Limitation.; III. Of Relation-Of Inherence and Subsistence (substantia et accidens). Of Causality and Dependence (cause and effect). Of Community (reciprocity between the agent and patient) and; IV. Of Modality-Possibility-Impossibility. Existence-NonExistence. Necessity-Contingence. Immanuel Kant, Critique of Pure Reason 62 J.M.D. Meiklejohn trans., 1990).

$7 \mathrm{SL}$, supra note 1 , at 327; $1 \mathrm{WL}$, supra note 1 , at 337.

8 SL, supra note 1, at 327; 1 WL, supra note 1, at 337 ("Einschiebung"). See David Gray Carlson, Hegel's Theory of Measure, 25 CARDOZO L. REv. 129, 135-37 (2003) for a discussion of Hegel's critique of Kant's tetrachotomy.

9 In the logical function of judgment, the understanding synthesizes the manifold into one object. KANT, supra note 6 , at 82-83. What judgment does is to bring the manifold under one of the categories. Id. at 83, 161. See Richard Dien Winfield, Autonomy and NormativITY: InVESTIGATIONS OF TRUTH, Right, AND BEAUTY 59 (2001) ("Kant is taken to task for metaphysically stipulating the character of the transcendental structure by conceiving it as a noumenal self determined through such unfounded devices as a metaphysical deduction of the categories, which simply adopts, with certain unargued modifications, the typology of judgment of received tradition."). 
Kant's Table of Logical Functions in Judgment ${ }^{10}$

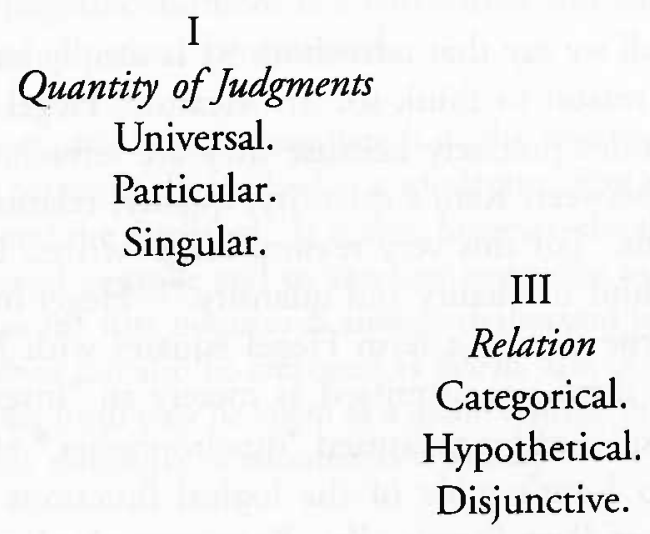

\section{IV \\ Modality \\ Problematical. \\ Assertorical. \\ Apodictical.}

All of Hegel's judgments can be found here. Of course, Hegel reverses Kant's priority and analyzes qualitative judgments first, consistent with the general priority of quality over quantity. He also renames the major headings. Instead of quantity-quality-relation-modality, Hegel gives us existence-reflection-necessity-notion.

It is certainly odd that Hegel should criticize the quadripartite Table of Categories while following the related Table of the Logical Functions of Judgment. This led Marcuse to remark:

Although Hegel convincingly demonstrates that what is meant and treated as judgment by ordinary linguistic usage aims at the same ontological content as discovered by him, the treatment of judgment in the formal logic is not fitted into this framework. Insofar as Hegel attempts to do so and insists on the traditional "table of judgments," he confuses and obscures the great aspects of his own doctrine. ${ }^{11}$

Yet, in spite of the above, Slavoj Žižek, a brilliant reader of the Science of Logic, defends Hegel:

10 KanT, supra note 6, at 56.

11 Herbert Marcuse, Hegel's Ontology and the Theory Of Historictty 127 (Seyla Benhabib trans., 1987). 
Let us immediately show our cards: the three judgments actually acquire a fourth because 'Substance is Subject'; in other words, the 'lack of identity' between subject and predicate is posited as such in the fourth judgement (that of the Notion). ${ }^{12}$

I want to join Žižek in defending Hegel's tetrachotomous judgment but I will do so on somewhat different terms. I will argue that it is not the last but the first judgment-the judgment of existence or inherence-that stands for the diversity of subject and predicate. The last judgment in fact vindicates a unity between identity and difference. The diverse subjectivity on display in the first of the judgments (which reappears in the last of the judgments) is an acknowledgement of an external reflection that haunts all parts of the Science of Logic.

Why are there four judgments? Let me now show my cards, like the dummy in a bridge game.

\section{TOUR DE JUdgement}

The notion is an individual. More precisely, it is universal, particular, and individual. We can put this colloquially: The notion is itself, its other, and the unity of itself and other. This can be expressed as $A=$ $\{A, B, C\}$, so that we have the following matrix:

$$
\begin{aligned}
& A=\text { Universality = Itself } \\
& B=\text { Particularity = Other } \\
& C=\text { Individuality = Unity of Self and Other }
\end{aligned}
$$

In the expression, $A=\{A, B, C\}, A$ stands on both sides of the equation as the individual in its abstract and concrete forms.

Let us now count the four judgments.

(1) Judgment of Existence. In the judgment of existence, some property of the subject is singled out arbitrarily: Hegel's example is "the rose is fragrant." ${ }^{13}$ It has the form $A=\{A, B, C\}$, but this is misleading. The rose is still a rose even if not fragrant. In this first judgment, $A$ is abstract and self-sufficient. It has no need of the predicate. Speculatively, $A$ is the lack of identity between itself and the notion. Therefore,

12 Slavoj Žıžek, For They Know Not What They Do: Enjoyment as a Political FACTOR 117 (1991).

13 SL, supra note 1 , at 633; 2 WL, supra note 1 , at 275. 
$A=\{A, B, C\}$, but also $A \neq\{A, B, C\} .^{14}$ At first, $A$ (the subject of notion's self-judgment) is everything; the predicate $\{A, B, C\}$ is nothing. Individuality rests with $A$, the abstract universal.

(2) Judgment of Reflection. Whereas the judgment of existence plucked some inessential predicate of the subject (the rose's fragrance), the judgment of reflection makes the predicate universal; the subject is merely an instance of the grander predicate: this thing is useful, or this man is mortal.

In the earlier judgment of existence, $A$ was what Hegel would call diverse from $\{\mathrm{A}, \mathrm{B}, \mathrm{C}\}$. Diverse things are finite immediate beings. Finite Beings must, on their logic, pass away. Being diverse, $A$ 's fate is to become nothing. ${ }^{15}$ Accordingly, in the judgment of reflection, the subject becomes nothing. The predicate $\{A, B, C\}$ is everything. ${ }^{16}$ Since the predicate is fixed, ${ }^{17}$ it now claims for itself the state of individuality at the expense of the subject. One way of expressing this is that abstract $A$ (the subject) turns into notional $B$ (particularity), so that now $B=\{A$, $B, C\}$.

(3) Judgment of Necessity. In the judgment of necessity, the genetic requirements of the subject are emphasized. Instead of "this individual is mortal," we have "all individuals are mortal."

In the judgment of reflection, the subject $(B)$ stated, "I do not exist. I am not the predicate $\{A, B, C\}$." Yet, if $\{A, B, C\}$ is diverse, it,

14 The supplementation of the equality with an inequality is pursuant to Hegel's very early instruction:

[T] he subject has a number of determinatenesses other than that of the predicate, and also that the predicate is more extensive than the subject. Now if the content is speculative, the non-identical aspect of subject and predicate is also an essential moment, but in the judgement this is not expressed. . . . To help express the speculative truth, the deficiency is made good in the first place by adding the contrary proposition ....

SL, supra note 1 , at $90-91 ; 1$ WL, supra note 1 , at 76 .

15 In other words:

Each partial and provisional element, therefore, fails to maintain itself in isolation, because its true and only nature is as a moment in the whole, so that it demands and goes over into its other to unite with it and to constitute a more complete and adequate exemplification of the ultimate universal principle of wholeness.

Errol E. Harris, The Spirit of Hegel 253 (1993).

16 Or, to be more precise, the predicate has a reflective relationship to the subject. The predicate is the appearance of a subject.

17 One of the consequences of the predicate's fixity is that the subject multiplies. The judgments of reflection are therefore singular, particular (where there are a class of subjects distinguishable from other subjects), and universal. 
too, must pass away as a finite being. But now $B$ and $\{A, B, C\}$ have a commonality. They both must pass away. This is their necessary connection. Connection (or copula) is the only thing that has staying power. Subject and predicate have no being for self. Individuality now resides in the unity of subject and predicate. $B$ morphs into $C$. Now $C=\{=$, $\neq\}$. $C$ represents the relation of self and other, in our colloquial formula. But shall the copula be $\{=\}$ or $\{\neq\}$ ? This is a matter of blind accident. All we know is that subject and predicate are related positively or negatively.

(4) Judgment of the Notion. The judgment of the notion is normative: this individual is as she should be, or this house is good.

The copula was front and center in the earlier judgment of reflection. But copulae cannot do without subject and predicate. These are the means by which $C$, the individual, expresses itself as copula. Individuality as copula now subsumes subject and the predicate. Notion now knows itself to be fully present in all its moments. Key here is the idea that there are notional moments and non-notional moments. But how can we tell which is which? Nothing in these moments betrays their true nature. About these moments there is nothing but doubtexcept that either the moments are notional or they are not. Meanwhile, $C=\{A, B, C\}$ and $C \neq\{A, B, C\}$. This is the judgment of the notion.

Across the four judgments, then, individuality travels around. It starts as the subject, it travels to the predicate, it travels to the copula, and it encompasses the copula and the extremes while still preserving the necessity of non-notional contingency. By this means, the four judgments replicate the logic of quality, quantity, actuality, and notionality.

\section{Tour de Syllogisme}

We cannot leave the matter here. The chapter (i.e., syllogism) that follows hard upon the funeral-baked meats of judgment witnesses a restoration of triunity. If there were four judgments, why not four syllogisms? Compare the subheadings of judgment and syllogism:

$\begin{array}{ll}\text { Judgment } & \text { Syllogism } \\ \text { Existence } & \text { Existence } \\ \text { Reflection } & \text { Reflection } \\ \text { Necessity } & \text { Necessity } \\ \text { Notion } & \end{array}$


Whereas judgment is tetrachotomous, syllogism is trichotomous. There is no syllogism of the notion. Why is trichotomy restored after an interregnum in which tetrachotomy runs riot?

Before I say why, let me summarize syllogism in plain terms. Present here is a very simple move in which Hegel turns skepticism on itself. To illustrate, take the contradictory statement, "There are no truths." This is a truth. Similarly, "there is only subjectivity" is an objectivity. These paradoxes go to the very heart of Hegel's logical system. If we take the statement "there are no truths" to be $A$, and if we take the truth to be notion, the predicate of $A$ is the truth. "There are no truths" can be expressed as $A \neq\{A, B, C\}$. But this is a truth, which implies $A$ $=\{A, B, C\}$.

Here is how syllogism proceeds:

(1) Syllogism of Existence. At the end of Judgment, the individual was the copula that colonized the extremes. This is syllogism. At this point, judgment ceased to be judgment. As G. R. G. Mure puts it, in the apodeictic judgment ("Notion is good"), the subject does not have goodness. To have is a relation of subject to predicate. Rather, the subject is goodness. There is a direct, performative connection between the extremes of the syllogism, which makes a distinction between subject and predicate no longer appropriate. ${ }^{18}$

Syllogism concerns proof, and proof for Hegel is the copula, or the middle term, between the extremes. But, between $\{A, B, C\}$, which of these is properly the middle term? Nothing in syllogism determines the matter definitively. An outside intelligence must establish this by mere dogmatic assertion. So the proposition that is proven is that all syllogisms are subjective. They prove nothing.

(2) Syllogism of Reflection. Notice the preceding theory of syllogism purports to be an induction. That syllogisms prove nothing presupposes that we have examined every single syllogism there ever was and, by empirical observation, have induced that failure is the universal predicate. But this is to say that failure is really in the syllogisms after all. This claim is not subjective but belongs to the object.

(3) Syllogism of Necessity. In the syllogism of reflection, every single syllogism was a failure. This implies that a single individual syllogism successfully represents every other. Syllogism presents us with perfect analogies. Analogy works if the individual is universal. The trait of one

18 G.R.G. Mure, The Philosophy of Hegel 136 (1965). 
is the trait of every other. If the earth is inhabited, the moon must be inhabited, as Hegel famously reasoned. ${ }^{19}$ This is the syllogism of Necessity. It stands for the fact that the individual notion is universal in its absolute necessity to particularize itself in the objective world. At this point, notion is objective.

Let us return, however, to the Syllogism of Existence. Significantly, it alone is tetrachotomous, like Judgment. The syllogism of Existence was supposed to be an objective proof, but it ended up depending on subjective judgment. In effect, syllogism falls back on the judgment of the notion. There is a precise coincidence between judgment of the notion and the syllogism of Existence. That is why there are four syllogisms of Existence. The fourth syllogism is the utter failure of all syllogisms to prove anything. It stands for a retreat to subjective judgment as its essential truth.

What I am suggesting is that there is a reverse double counting between judgment and syllogism. Judgment of the notion is exactly the same as the syllogism of Existence. The trichotomy of syllogism therefore swallows the excess in judgment. What was fourth in judgment becomes first in syllogism. If the fourth judgment shares an identity with the first syllogism (of three), triunity suppresses the tetrachotomy unloosed by judgment. The system renders itself apparently triune again.

\section{Why Four ART ThOU?}

With these brief tours de jugement et syllogismes, we can finally say what the judgmental tetrachotomy means in relation to Hegel's entire logical system.

Žižek claims that the system is haunted by the silent fourth and that the fourth judgment represents the manifestation of this vanishing mediator. ${ }^{20}$ Žižek compares the silent fourth to the dummy in contract bridge. In bridge, the partner who first names the trumps seizes control of the partnership. ${ }^{21}$ The silent partner must lay down her hand and remain silent. Table talk, though common, is strictly forbidden. In her silence, the dummy nevertheless controls the game. All players react to the dummy.

19 SL, supra note 1, at 692; 2 WL, supra note 1 , at 339.

20 Žižek, supra note 12 , at 179.

21 Id. 
A silent fourth occupies the entire Objective Logic. ${ }^{22}$ Early on, the understanding emerges as such when it proposes that becoming is a determinate being. Hegel writes, "That the whole, the unity of being and nothing, is in the one-sided determinateness of being is an external reflection; but in the negation, in something and other and so on, it will come to be posited." 23 Here, Hegel says that this conclusion of the Understanding - that becoming is-is not strictly necessitated as a matter of logic. It comes from the outside. This external reflection is the silent fourth that energizes the logic.

Later, Hegel writes that quantity depends upon an other for its determination. Who is this other but the silent fourth? Of quantity, Hegel writes that "determinateness in general is outside itself." ${ }^{24}$ Quantity is "posited as self-repelling, as in fact having the relation-to-self as a determinateness in another something (which is for itself)." 25 This means that quantitative distinction is externally imposed. Quantity requires a silent fourth-an external mathematician who counts.

Measure likewise points to a measurer-a silent fourth external to the logic itself that raises the temperature of things in order to produce a qualitative change. Qualitative change is accomplished by quantitative change, which is defined as that which comes from the outside. "As a quantum [Measure] is an indifferent magnitude open to external determination and capable of increase and decrease. But as a measure it is also distinguished from itself as a quantum, as such an indifferent determination, and is a limitation of that indifferent fluctuation about a limit." 26 Thus, Measure stands for susceptibility to outside manipulation. A silent fourth is directly implied by Measure.

Essence points to the fourth whenever the concept of external reflection is invoked. External reflection implies a thing's indifference to what an outside intelligence thinks of it. ${ }^{27}$ This external intelligence is likewise the silent fourth-the subjectivity that being requires in order to endure over time.

22 See Clark Butler, Hegel's logic: Between Dialectic and History 232 (1996) ("Our own subjectivity is concealed in our objective world").

23 SL, supra note 1 , at 110; 1 WL, supra note 1 , at 97.

$24 \mathrm{SL}$, supra note 1 , at 185; $1 \mathrm{WL}$, supra note 1 , at 177.

$25 \mathrm{SL}$, supra note 1, at 185; 1 WL, supra note 1, at 177.

$26 \mathrm{SL}$, supra note 1 , at 334; 1 WL, supra note 1 , at 344.

27 For this reason, external reflection is "a positing of the immediate. ..." SL, supra note 1 , at 403; $1 \mathrm{WL}$, supra note 1 , at 18 . 
There is, however, a strange reversal when we reach the notion. The notion is the result of finite being having passed away. What remains standing is the notion. But passing away is always also a preservation. This is the law of sublation. As all Hegelians know, aufheben means simultaneously to cancel and to preserve.

What is preserved in notion is a ghostly memory of Being. ${ }^{28}$ Being is inwardized or recollected immediacy or abstraction. ${ }^{29}$ This now becomes the silent fourth to notion-the thing that traumatizes the subject and keeps it in motion. Whereas the silent fourth had been a subjective intrusion on the object, now the silent fourth is an objective intrusion on the subject. This is what provokes the system to identify the universal as the first element of the notional trinity. This act of abstraction is precisely what the notional individual cannot swallow. This is why the notion is self-divisive and generative of the realm of judgment. There is the absent reality that notion must fill out through the dumb show of judgment.

Ironically, the silent fourth in the realm of being was the subjectivity yet to come. Now the silent fourth becomes the trauma of the being that was supposedly repressed. ${ }^{30}$

The silent fourth finally speaks in judgment. It is the extraneous, mad, external mediator that binds the system together. It turns out that Shemp was truly in charge of the Stooges all along, even though he appeared at the dusk of their long career, when the owl of Stooge Minerva finally flew.

Precisely where does this mad moment of disjunction (which secretly conjoins all) appear? It is present in the judgment of existence. But it is swallowed again by the predicate, reappears in the copula and continues into syllogism.

28 See Ermanno Bencivenga, Hegel's Dialectical Logic 12 (2002) ("Hegel's logic is one of recollection, of memory, its necessity is the internal consistency of what is remembered ....") (footnote omitted).

29 Erinnerung can be translated as inwardization or recollection. Thus, Miller's translation reads: "Not until knowing inwardizes, recollects itself out of immediate being, does it through this mediation find essence." SL, supra note 1, at 389; 2 WL, supra note 1, at 3 ("Erst indem das Wissen sich aus dem unmittelbaren Sein erinnert, durch diese Vermittlung findet es das Wesen.").

30 BUTLER, supra note 22, at 233 ("The subjective self-concept encounters an object which is the dead remnant of that very subjective self-concept, a remnant left over from its incipient historical self-construction."). 
It even survives syllogism. The disjunctive syllogism represents the point that the universal subject is all its predicates, but this subject still requires a non-notional object-a non-universal that constitutes a fourth to triune subjectivity. The subject's object must eventually be rendered notional. Through the dialectic of objectivity (mechanismchemism-teleology), the silent fourth is further developed until, in Teleology, the silent fourth is revealed to be the subject's very own self. Two subjects face each other in Teleology. The silent fourth itself becomes three. Shemp is now Moe, Larry and Curly. That is the very Idea of Hegel's Science of Logic.

Yet, neither is Idea exempt from the trauma of the silent fourth. In Hegel's very last chapter, method and subject matter supposedly conjoin. ${ }^{31}$ Method is the one and only subject. We have the Understanding, its negation, Dialectical Reason, and the Negation of the Negation-Speculative Reason. But when all is said and done, there is a hole in the whole. Negation of the negation is not the restoration of the positive thing originally negated. It is less than that. This very absence is the silent fourth-the non-notional individual that guarantees that Logic never ends. It is only by virtue of the silent fourth that Logic is a circle. What traumatizes the method is the silent fourth rendered manifest for a moment in Judgment.

\section{CONCLUSION}

Hegel's method is traditionally viewed as the passage from immediate Understanding to mediated Dialectical Reason to Speculative Reason, which holds the prior two positions in tension. Yet there is always a fourth. Method must work on something. This something is an irrational, non-methodical material without which the Heracleitan flux cannot flow. In the judgment chapter, this silent fourth, like Garbo, finally speaks. In judgment, not only must the notion objectify itself in a notional way, it must judge its non-self-say what this is. The three notional moments, together with the non-notional self, comprise Hegel's four judgments.

31 Angelica Nuzzo describes how method ultimately stands over against all of the "erroneous" moments of the logic that precedes it. Angelica Nuzzo, The End of Hegel's Logic: Absolute Idea as Absolute Method, 3 Cardozo Pub. L. Pol'y and Ethics J. 203 (2005). 